\title{
Das concepções de Ciência à disponibilização de produtos educacionais: uma possibilidade para aprimorar práticas pedagógicas no Ensino de Ciências
}

From the conceptions of Science to the availability of educational products: a possibility to improve pedagogical practices in the Science Teaching

Francisco Sidomar Oliveira da Silva (iD https://orcid.org/0000-0002-7130-4840

Universidade Federal do Acre, Universidade Estadual Paulista Júlio de Mesquita Filho (Bauru) sydomar_czs@icloud.com

Nubia Maria de Castro Oliveira (D) https://orcid.org/0000-0001-7253-4827 Universidade Estadual de Roraima, Secretaria de Estado de Educação do Acre nubia.mc@hotmail.com

Josenilson da Silva Costa (iD https://orcid.org/0000-0002-5564-3105 Universidade Federal do Acre, Secretaria de Estado de Educação do Acre nilson_jsc@hotmail.com

Aline Andréia Nicolli iD https://orcid.org/0000-0001-6594-0560 Universidade Federal do Acre aanicolli@gmail.com

\section{Resumo}

O presente estudo apresenta os resultados de uma pesquisa que objetivou conhecer as concepções de Ciência de futuros professores da Educação Básica e, depois, refletir sobre como tais concepções podem interferir nas práticas pedagógicas desenvolvidas no Ensino de Ciências. Os dados foram coletados com 81 estudantes, concludentes dos Cursos de Licenciatura em Ciências Biológicas e Química e sistematizados com a utilização do software Iramuteq (Interface de $R$ pour les Analyses Multidimensionnelles de Textes et de Questionnaires). A análise dos dados evidenciou que as concepções, de forma geral, resultam de uma abordagem elementar e superficial da História da Ciência, nos cursos de formação de professores, e que tal situação pode resultar, a nosso ver, em implicações negativas à abordagem dos conteúdos em aulas de Ciências, uma vez que os mesmos tornam-se objetos de estudo sem estarem situados no tempo e na história e, por conseguinte, induzem os sujeitos a pensar a Ciência como sendo algo distante do seu tempo, da sua história e de suas vidas. Tais constatações fizeram emergir a elaboração de produtos educacionais, um vídeo e um curso on-line, de curta duração, com intuito divulgar a História da Ciência e, sempre que possível, subsidiar a abordagem da referida temática em salas de aula de Ciências.

Palavras-chave: Formação Docente. Prática Pedagógica. Ensino de Ciências. 


\begin{abstract}
The present study presents the results of a research that aimed to know the conceptions of Science of future teachers of the Basic Education and, then, reflect on how such conceptions can interfere in pedagogical practices developed in the Science Teaching. The data were collected with 81 students, completing the Undergraduate Courses in Biological Sciences and Chemistry and systematized with the use of the software Iramuteq (Interface de $R$ pour les Analyses Multidimensionnelles de Textes et de Questionnaires). The data analysis showed that the conceptions, in general, result from an elementary and superficial approach to the History of Science, in the teacher training courses, and that this situation may result, in our view, in negative implications to the approach of the contents in Science classes, since they become objects of study without being situated in the time and history and, therefore, they induce the subjects to think the Science as something distant from their time, their history and their lives. These findings led to the emergence of educational products, a video and a short-term online course, in order to disseminate the History of Science and, whenever possible, to support the approach of this theme in Science classrooms.
\end{abstract}

Keywords: Teacher Training. Pedagogical Practice. Science Teaching.

\title{
Introdução
}

Os Mestrados Profissionais foram regulamentados, em âmbito nacional, pela Portaria Capes $n^{\circ}$ 80, de 16 de dezembro de 1998. Nela são explicitadas as principais características e objetivos dos Mestrados Profissionais e, dessa forma, destaca-se que os mesmos foram reconhecidos como possibilidade de ampliação da formação profissional conquistada na graduação. (BRASIL, 1998)

Para isso, devem, os Mestrados Profissionais, possuir estrutura curricular que articule o ensino com a aplicação profissional dos mestrandos e apresentação de trabalhos de conclusão de curso que demonstrem domínio do objeto de estudo e, da mesma forma, viabilizem a promoção de bens e serviços em forma, no caso de mestrados profissionais na área de ensino, de produto educacional.

Destaca-se, assim, que os Mestrados Profissionais objetivam garantir o desenvolvimento de pesquisas que extrapolam o limite das discussões teóricas, pois objetivam além dela a elaboração e disponibilização de produtos educacionais como alternativa para enriquecer as abordagens pedagógicas e, consequentemente, as intervenções desenvolvidas em salas de aula.

A partir do exposto é que, nesse artigo, relatamos aspectos referentes ao desenvolvimento de duas pesquisas realizadas durante a frequência em Cursos de Mestrados Profissionais em Ensino de Ciências e Matemática, com intuito de primeiro problematizar as concepções de Ciência defendidas por futuros professores da Educação Básica e suas implicações para atuação profissional em salas de aula. Depois, em decorrência da problematização realizada, ao longo da pesquisa, relataremos como emergiram as propostas dos produtos educacionais que foram elaborados e disponibilizados à comunidade, quais sejam: um vídeo e um curso on-line de curta duração que abordam a História da Ciência. 
Sendo assim, no texto proposto optamos por trazer uma breve discussão teórica acerca dos objetivos da elaboração e disponibilização de produtos educacionais, bem como uma descrição teoricamente situada dos produtos elaborados ao longo de nossas pesquisas. Finalizaremos indicando ao leitor algumas considerações sobre a utilização dos produtos disponibilizados como objeto de formação continuada para docentes, ou ainda, de recurso didático para aprimorar práticas pedagógicas em salas de aulas de Ciências, na Educação Básica.

\section{Produtos educacionais: elementos que justificam suas elaborações}

Como dito anteriormente, a elaboração e disponibilização de produtos (patentes, serviços, softwares, jogos) surgem no bojo dos estudos desenvolvidos quando da frequência em Cursos de Pós-graduação stricto sensu caracterizados como profissionais. Neles é que os estudantes são desafiados a desenvolver suas pesquisas e, com elas, ou ainda, para além delas ou em decorrência delas, propor um produto que poderá de alguma forma impactar positivamente na atuação de outros profissionais da área.

Para atender ao exposto iniciaremos nossas reflexões indicando que os produtos educacionais ora apresentados emergiram do desenvolvimento de pesquisas realizadas ao longo do período no qual frequentamos o Mestrado Profissional em Ensino de Ciências e Matemática, na Universidade Federal do Acre e o Mestrado Profissional em Ensino de Ciências, na Universidade Estadual de Roraima.

Ambas as pesquisas desenvolvidas contaram com a realização de uma ampla discussão teórica acerca da História da Ciência para, a partir dela, fazermos primeiro a análise dos dados coletados, bem como entender quais concepções de Ciência são frequentemente defendidas por professores que atuam na Educação em Ciências e, depois, refletir sobre como tais concepções podem interferir suas práticas em sala de aula.

Por fim, foi da análise teórica e dos dados empíricos que surgiu a ideia de elaboração dos produtos, de forma que eles pudessem efetivamente ser colocados à disposição da comunidade para promover melhorias nos processos de formação continuada de docentes, bem como nas práticas pedagógicas desenvolvidas em salas de aula de Ciências.

\section{Elementos teóricos, metodológicos e empíricos que suscitaram a elaboração dos produtos educacionais}

\section{Elementos teóricos}

É indiscutível o poder e a influência da Ciência frente ao desenvolvimento das sociedades. Mediante o avanço da Ciência, por exemplo, sociedades, tradições, economias e pensamentos são criados, moldados ou/e transformados. Assim, a compreensão se faz necessária a todos os agentes que constituem uma sociedade. No entanto, segundo Lopes (1996, p.106), 
Ainda persiste um cientificismo que presta um desserviço à Ciência, na medida em que a mitifica. As ideias científicas, que deveriam ser compreendidas como relativas e provisórias, essencialmente humanas, são transformadas em ídolos; a Ciência ao invés de ser compreendida como uma obra de cultura torna-se um objeto de culto e seu sucesso social se volta contra o próprio conhecimento científico, por reconduzi-lo ao plano de mito que ele pretende superar.

Mesmo com os diversos avanços na sociedade, ainda há aqueles que propagam o conhecimento científico como verdade absoluta, algo inquestionável. Muitos ainda compreendem a Ciência como pronta e acabada, algo imutável, não sujeita às influências da subjetividade, sendo, portanto, para eles, científico apenas o que fora provado/testado por meio dos processos de observações e experimentação.

Mas, então, o que seria Ciência? Esse questionamento que muito instiga e que tem se tornado, ao longo dos tempos, o cerne de investigações desenvolvidas por pesquisadores de diferentes áreas, é apresentado por Chalmers (1993) em seu livro "O que é Ciência afinal?", no qual, em linhas gerais, o autor procurou analisar as concepções de Ciência na modernidade. Indica de início que,

\begin{abstract}
Os desenvolvimentos modernos na Filosofia da Ciência têm apontado com precisão e enfatizado profundas dificuldades associadas à ideia de que ciência repousa sobre um fundamento seguro adquirido através de observação e experimento e com a ideia de que há algum tipo de procedimento de inferência que nos possibilita derivar teorias científicas de modo confiável de uma tal base. (CHALMERS,1993, p. 13).
\end{abstract}

Com isso, deve-se compreender que não há formação e nem transformação no tocante ao conhecimento científico por meio exclusivo do processo de experimentação. O conhecimento científico passou por transformações, descobertas e redescobertas ao longo dos tempos, sendo influenciado pelos anseios e aflições de cada geração ocorrendo, assim, uma espécie de metamorfose, conforme Prigogine e Stengers (1997). A Ciência faz parte do complexo de cultura a partir do qual, em cada geração, os homens tentam encontrar uma forma de coerência intelectual.

Em sua obra, Granger (1994) enfatiza que a característica básica da Ciência é uma maneira de olhar o mundo, não se tratando assim de uma metodologia, isto porque existe certo pluralismo metodológico nas Ciências e, por isso, nos apresenta três aspectos que julga fundamentais para compreender o que denominamos como visão científica e que nos impulsiona a realizar reflexões acerca da finalidade da Ciência. Vejamos:

O primeiro traço característico é de que a Ciência é uma visão da realidade: a Ciência é uma representação abstrata, sob a forma de conceitos, que se apresenta, com razão, como uma representação, não como um reflexo, do real. Segundo, a Ciência visa a objetos para descrever e explicar, e não para agir, como num grande jogo do conhecimento. Terceiro, a Ciência se preocupa com critérios de validação. Contudo, não se trata de uma validação pelo experimento: a verificação de um fato científico - que por ser científico já é uma construção - depende de uma interpretação ordenada, dentro de uma teoria explícita. (GRANGER, 1994, p. 51). 
Temos na obra de Gaston Bachelard (1997), por sua vez, um aprofundamento da finalidade da Ciência, pois o autor não objetiva estabelecer o melhor caminho para a produção de conhecimento e, por isso, mantendo sua coerência com a perspectiva histórica, não se preocupa com critérios de demarcação entre Ciência e não Ciência.

O autor (1997) critica a concepção empirista atribuída à Ciência, pois, segundo ele, há a necessidade de uma verificação teórica no fato científico, isto para classificálo como legalmente científico e, da mesma forma, faz críticas também à concepção cartesiana sobre produção de conhecimento científico.

Nessa perspectiva, tem-se que a Ciência não produz uma verdade pronta, acabada, imutável. Produz, por sua vez, verdades temporárias, sujeitas a questionamentos e possíveis alterações. Logo, não há critérios universais ou externos com a finalidade de realizar julgamentos a uma Ciência. De acordo com Lopes (1999) cada Ciência produz sua verdade e organiza os critérios de análise da veracidade de um conhecimento. Mas a lógica da verdade atual da Ciência não é a lógica da verdade de sempre: as verdades são sempre provisórias.

Além disso, Chalmers (1993) indica a necessidade de cada área do conhecimento "ser julgada" pelos próprios méritos, pela investigação de seus objetivos, e, em que extensão é capaz de alcançá-los, uma vez que,

\begin{abstract}
Os julgamentos relativos aos objetivos serão relativos à situação social. Os julgamentos sobre algum ramo obscuro da lógica matemática ou da filosofia analítica podem ter um peso considerável, em termos do prazer estético que proporciona aos seus participantes, para alguma classe privilegiada de uma sociedade rica, mas um peso pequeno para uma classe oprimida de um país do Terceiro Mundo. O objetivo do controle tecnológico sobre a natureza é de grande importância em uma sociedade em que problemas sociais extremamente urgentes necessitam um aumento do controle tecnológico, e deve ter importância menor em nossa sociedade, em que aparentemente os problemas sociais mais urgentes são antes exacerbados que aliviados por maiores avanços no controle tecnológico. (CHALMERS, 1993, p. 212).
\end{abstract}

Ainda para o autor, a questão "o que é Ciência?" é falaciosa, enganosa e arrogante, pois nos direciona à visão de uma única categoria de Ciência, excluindo diversas outras formas de conhecer e compreender o conhecimento. Segundo o autor, os filósofos, por exemplo, não têm recursos que os habilitem a legislar a respeito dos critérios que precisam ser satisfeitos para que o conhecimento que produzem seja considerado aceitável ou "científico". Segundo ele,

Cada área do conhecimento pode ser analisada por aquilo que é. Ou seja, podemos investigar quais são seus objetivos - que podem ser diferentes daquilo que geralmente se consideram ser seus objetivos — ou representados como tais, e podemos investigar os meios usados para conseguir esses objetivos e o grau de sucesso conseguido. Não se segue disso que nenhuma área do conhecimento possa ser criticada. Podemos tentar qualquer área do conhecimento criticando seus objetivos, confrontando-a com meios alternativos e superiores de atingir os mesmos objetivos e assim por diante. Desse ponto de vista não precisamos de uma categoria geral 'Ciência', em relação à qual alguma área do conhecimento pode ser aclamada como Ciência ou difamada como não sendo Ciência. (CHALMERS, 1993, p. 213).

Revista de Estudos e Pesquisas sobre Ensino Tecnológico, v. 6, e123120, 2020. 
Ao falar de Ciência, nos dias atuais, importa também mencionar os escritos de Maturana e Varela (2001) e de Morin (2000, 2002 e 2010). Para Maturana e Varela (2001) o envolvimento com questões relacionadas à Biologia da cognição, produzse uma epistemologia tida por muitos como original. Esta, por sua vez, promove novas reflexões especialmente no que tange o ser, o real, o existir, o observar e o conhecer. Em linhas gerais, os autores acreditam no caráter biológico na construção e reconstrução do conhecimento e, por isso, indicam que:

Toda experiência cognitiva inclui aquele que conhece de um modo pessoal, enraizado em sua estrutura biológica, motivo pelo qual toda experiência de certeza é um fenômeno individual cego em relação ao ato cognitivo do outro. (MATURANA; VARELA, 2001, p.22).

Os autores defendem que o conhecimento é constituído pelas próprias experiências do indivíduo. Logo, é compreendido como algo inerente aos seres vivos e, por isso, é apresentado como uma ação efetiva da Biologia, tornando possível a diversidade existente na natureza e a unicidade existente nos seres vivos. Utilizando o aforisma empregado pelos próprios autores, viver é conhecer. Viver é a ação efetiva no existir como ser vivo. (MATURANA; VARELA, 2001).

É, no entanto, no cenário social tomado pelas inquietações e incertezas originadas pelo fim da modernidade que Edgar Morin tem suas ideias ascendidas, pois suas concepções referentes à Ciência, ao conhecimento, à razão e à humanidade possuem, de um lado, estreitas relações com as ideias de Maturana e Varela (2001) e, de outro, realizam fortes críticas ao denominado paradigma da simplificação. Segundo o autor,

Até o início do século XX - quando ela entra em crise - a Ciência "clássica" se fundamentou sobre quatro pilares da certeza que têm por causa e efeito dissolver a complexidade pela simplicidade: o princípio da ordem, o princípio de separação, o princípio de redução, o caráter absoluto da lógica dedutivo-identitária. (MORIN, 2000, p. 95).

Da mesma forma, segundo ele, o que encontramos, na atualidade, é uma sociedade limitada que não responde as inquietações que se apresentam pelos seus constituintes. Por isso, exige-se do social e do científico novas categorias de compreensão e ação sobre os fenômenos e elas podem surgir apenas por meio do pensamento completo, visto que somente ele tem a capacidade de aceitar e lidar com as incertezas e a dialogicidade, por exemplo. Temos então, em Morin (2000), uma concepção de transformação científica que se pauta, prioritariamente, na complexidade, ou seja, na teoria do pensamento complexo. Dessa forma,

O paradigma científico tradicional, alicerçado nos "pilares da ordem, da separabilidade e da razão", seria insuficiente para comportar a complexidade que não mais admite ser negada. As resistências à complexidade, tão comuns àqueles que se afirmam sob a Ciência clássica, dissolvem-se diante do que revelam os conceitos e teorias articuladas na "nova Ciência". As contribuições desta nova Ciência redimensionaram o alcance do conhecimento humano, lançando luzes sobre alguns pontos e profundas interrogações sobre outros. (MORIN, 2000, p.199).

Os escritos relativos à Ciência que também merecem, a nosso ver, destaque, ao longo do presente texto, são os do autor Ernest Mayr (2008). Para ele a Ciência é um processo contínuo de análise de problemas e sucessivas tentativas para 
resolvê-los, com o intuito de melhor compreendermos o mundo no qual estamos inseridos.

Segundo o autor (2008), a Ciência sofre diversas influências que se relacionam ao próprio campo de pesquisa, como também às influências da política, cultura e sociedade. Ou seja, as influências externas são as que mais afetam o desenvolvimento do pensamento científico e, por isso, por exemplo, a valorização da Física, o fisicalismo, influenciou fortemente o desenvolvimento teórico da Biologia tornando-a, de certa forma, inferior.

Além disso, apresentaremos, para finalizar a presente discussão, a Ciência entendida como construção humana, não devendo ser, portanto, compreendida como munida exclusivamente de aspectos positivos ou negativos, ou ainda, responsável somente por gerar progressos ou retrocessos. Nessa perspectiva, encontramos nos escritos de Chassot (2003) a defesa de uma Ciência que se faz falível, constituída por verdades transitórias que cumpre a função de atribuir algumas respostas às realizações humanas. Nessa perspectiva, a Ciência pode ser considerada uma linguagem construída pelos homens e pelas mulheres para explicar o nosso mundo natural.

Fazem defesa semelhante Collins e Pinch (2003), autores que apresentam reflexões contundentes acerca do poder da Ciência, chamando, porém, a atenção a possibilidade dela se apresentar de forma desajeitada e perigosa. Segundo os autores (2003), a Ciência não pode ser responsabilizada pelos seus erros, já que eles são erros humanos. Em síntese, defendem que, embora possuidora de rigor científico e metodológico, a Ciência se abre para uma diversidade de possibilidades de construções humanas, que embora detentora de poderes imensuráveis, pode ser volátil a depender de quem a 'controla'.

\title{
Elementos metodológicos
}

Ambas as pesquisas são caracterizadas como sendo de natureza qualitativa, pois se propuseram a conhecer as concepções de Ciência de futuros docentes de Educação Básica, de forma a estabelecer possíveis relações delas com as práticas pedagógicas desenvolvidas no Ensino de Ciências. Tal caracterização é ratificada a seguir,

\begin{abstract}
A pesquisa qualitativa responde a questões muito particulares. Ela trabalha com o universo de significados, motivos, crenças, aspirações, valores e atitudes, o que corresponde a um espaço mais profundo das relações, dos processos e dos fenômenos que não podem ser reduzidos a operacionalizações de variáveis. (MINAYO, 1998, p.22).
\end{abstract}

Nas investigações realizadas, os sujeitos, 46 concludentes do curso de Ciências Biológica - Licenciatura e 35 concludentes do Curso de Química - Licenciatura, da Universidade Federal do Acre, responderam à questão: O que é Ciência para você?

Os dados foram coletados por meio da aplicação, em sala de aula, de um instrumento impresso e sistematizados com a utilização do software Iramuteq (Interface de $R$ pour les Analyses Multidimensionnelles de Textes et de Questionnaires). Trata-se de um programa informático gratuito, que se ancora no software $\mathrm{R}$ e permite diferentes formas de análises estatísticas do corpus textual coletado. Para esta pesquisa optamos pela organização de "nuvem de palavras" que "[...] agrupa e as organiza graficamente em função da sua frequência, na 
medida em que possibilita rápida identificação das palavras chave de um corpus." (CAMARGO; JUSTOS, 2013, p. 516).

A análise dos dados empíricos obtidos foi desenvolvida tendo como base as discussões teóricas apresentadas pelos autores escolhidos para fundamentar nossos estudos.

\section{Elementos empíricos}

Como dito anteriormente, os dados foram coletados com 81 estudantes, concludentes dos Cursos de Licenciatura em Ciências Biológicas e Química. Ou seja, futuros professores da Educação Básica. Das respostas obtidas à questão: $O$ que é Ciência para você? foi possível fazer algumas inferências que apresentamos a seguir:

$\mathrm{Na}$ figura 1 observa-se que as palavras de maior frequência são: conhecimento, estudo, vida, área e pesquisa. As palavras apresentam relação com a Ciência na perspectiva de busca/construção de conhecimento. Exemplificam o exposto, as respostas que apresentamos a seguir: "Ciência é o fato de questionar os saberes já existentes, ou os fenômenos naturais, e a partir desses questionamentos achar uma resposta." (E39), ou ainda "Descobrir novas fontes de conhecimento sobre a vida" (E32), ou ainda, "Pesquisar, conhecer e entender todas os tipos de interação existentes na terra." (E27)

No entanto, cabe ressaltar que essa concepção apresentada pelos discentes está diretamente relacionada à Biologia, especialmente quando se observa as palavras vida e estudo.

Figura 1-O que é Ciência para os concludentes em Ciências Biológicas

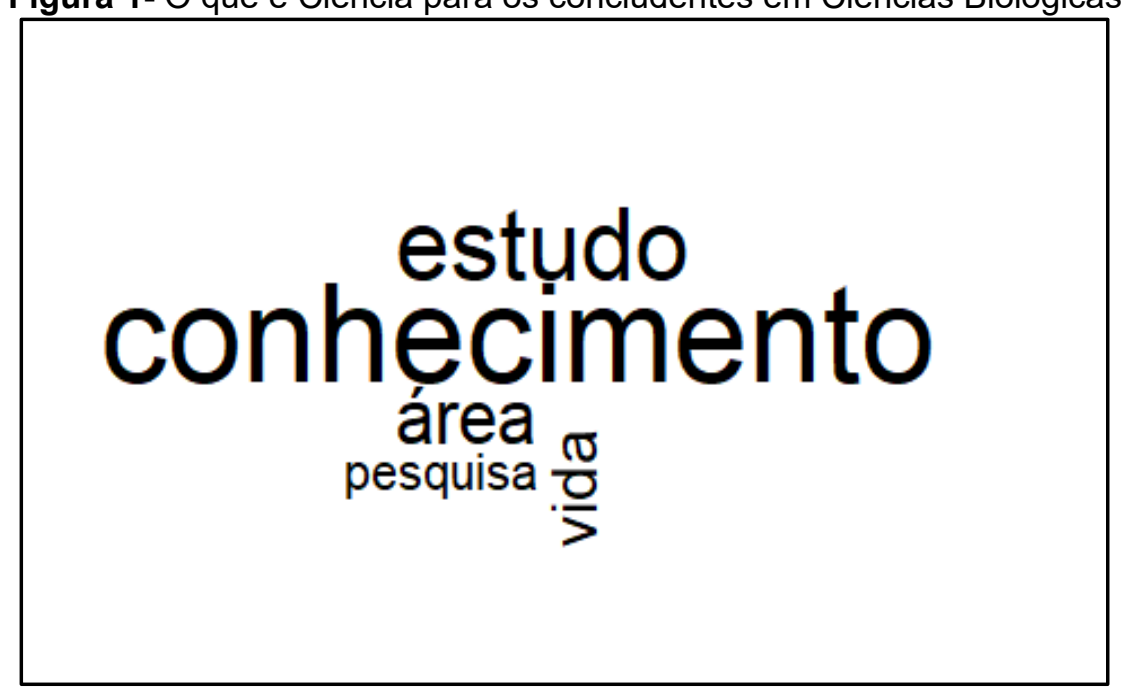

Fonte: Autores, 2019.

Na Figura 2, evidenciamos as palavras relacionadas à Ciência que mais foram citadas pelos estudantes do Curso de Licenciatura em Química. A análise revela que a maioria dos estudantes associou Ciência a método científico e aos fenômenos da natureza. Além disso, destacaram-se também as palavras tecnologia, experimentação e conhecimento. Esta associação é provavelmente originada das possíveis aulas experimentais cursadas na graduação e da abordagem naturalista do conhecimento escolar/acadêmico. 
No primeiro caso, provenientes das atividades realizadas em laboratório que geralmente enfatizam o rigor metodológico, a experimentação e o uso da tecnologia e, no segundo, da abordagem dos conteúdos de forma descontextualizada, ou seja, a compreensão dos fenômenos da natureza por si, isolados do contexto dos sujeitos e da história da Ciência. Exemplificam tais percepções as falas dos estudantes E8, E15, E21 e E25 respectivamente, vejamos: "É uma maneira de conceituar e estudar o mundo das transformações", "É o estudo de compreender o meio onde vivemos suas estruturas orgânicas", "É uma forma de conseguir conhecimento através do método científico", ou ainda, "Ciência é o ramo do conhecimento humano pautado no método científico.".

Figura 2- O que é Ciência para os concludentes em Química

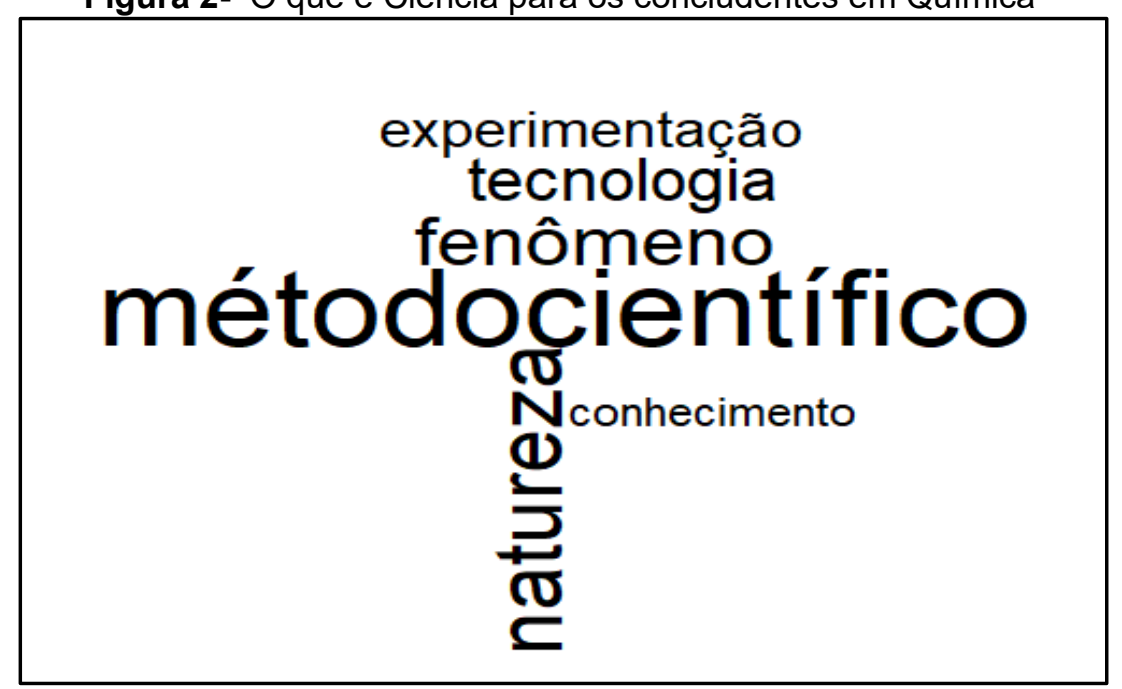

Fonte: Autores, 2019.

Em se tratando de análise conjunta dos dados, apresentados nas figuras 1 e 2, podemos dizer que a Ciência é, na perspectiva dos sujeitos de pesquisa, um conhecimento derivado dos dados experimentais obtidos por meio de experimentação, estudos, pesquisas, que envolvem especialmente os fenômenos da natureza. Os estudantes parecem acreditar que a Ciência está diretamente relacionada às atividades práticas, desenvolvidas em laboratório, e que a observação é a fonte e a função do conhecimento científico.

Dito de outra forma, os dados nos levam a perceber que os estudantes definem Ciência como resultado da comprovação de fenômenos da natureza e que eles enfatizam o rigor metodológico, o desenvolvimento de estudos e de pesquisas, bem como a utilização de tecnologia como pressupostos para a produção do conhecimento.

Nessa perspectiva, quando se trata de perceber a Ciência como algo comprovado tem-se a mesma subentendida nas respostas que a relacionam como algo produzida em laboratórios, por meio da utilização de ferramentas que permitem estudar tudo (a mais minúscula partícula ao universo como um todo), de forma criteriosa.

Por outro lado, em se tratando da Ciência munida de rigor científico destacam-se as percepções de que o conhecimento humano se origina da observação, pois é por ela que se pode chegar à indução para fundamentar os fatos e as teorias e, consequentemente, a construção de verdades prontas e acabadas. 
Ante o exposto, além de identificarmos aspectos acerca das concepções de Ciência, é importante compreender, ao atuar como professor, seja no Ensino de Ciências, seja em qualquer outra área, que existe/deveria existir uma diversidade de concepções/percepções possíveis, a partir das quais deve-se construir a abordagem pedagógica de forma crítica, histórica e situada social e culturalmente.

Sendo assim, embora os nossos dados não nos permitam considerar, por exemplo, os pressupostos do pensamento complexo, de Morin (2010) pois é preciso reconhecer que, por meio dele, poderemos restituir um conhecimento que se encontra adormecido, reagrupando unidade e diversidade. Para o autor, os pesquisadores deveriam inscrever a competência especializada num contexto natural, na globalidade. Ou seja, o autor propõe que "[...] deve-se contextualizar cada acontecimento, pois as coisas não acontecem separadamente. Os átomos surgidos nos primeiros segundos do Universo têm relação com cada um de nós." (MORIN, 2010, p.78).

$\mathrm{Na}$ concepção de Morin (2010), ao se considerar o paradigma tradicional dominante (Ciência moderna clássica) e o paradigma da complexidade - emergente (Ciência pós-moderna/contemporânea) compreende-se que o conhecimento foi fragmentado. Desta forma, o resultado apresentado foi um afastamento entre Ciência e Filosofia, alimentando outras crises na própria Ciência, causando outra separação, a separação entre as ciências naturais e as ciências sociais.

As análises nos mostram que muitos estudantes, sujeitos desta pesquisa, apresentam concepções fortemente ligadas a uma visão de Ciência como produto de experimentos, métodos científicos e observação de fenômenos, o que desconsidera a possibilidade de a Ciência ser dinâmica, possuidora de uma linguagem acessível a todos para que, de fato, exista um desenvolvimento científico regulado pela sociedade.

Nota-se ainda nas concepções apresentadas, tanto pelos estudantes de Ciências Biológicas quanto pelos estudantes de Química, um distanciamento entre os sujeitos (produtores) e o conhecimento (produto), o que evidencia uma visão fragmentada da Ciência. Da mesma forma, ao conceber Ciência como produto, apenas na perspectiva de sua área de atuação, os nossos sujeitos de pesquisa se voltam, quando estudantes de Ciências Biológicas, ao conhecimento da vida e, quando estudantes de Química, ao conhecimento de fenômenos naturais.

Percebe-se também, em decorrência das análises, que muitos estudantes acreditam que o conhecimento é necessário apenas no âmbito do fazer científico, desconhecendo ou desconsiderando a importância do conhecimento para o fazer pedagógico. Assim, se pensarmos nas implicações de tais concepções para o ensino, notaremos que, de certa forma, nossos sujeitos de pesquisa deixam de lado, por exemplo, os fundamentos da Pedagogia Freiriana $(1981,1987,1997)$ amplamente discutidos nos dias atuais, sendo que a multidisciplinaridade, a interdisciplinaridade, a interação dos sujeitos e a comunicação entre as diversas áreas se fazem necessárias à efetivação de processos de ensino e aprendizagem, em salas de aula de maneira significativa.

Assim, ao perceber que a Ciência não é um fato isolado, de responsabilidade exclusiva de uma pequena parcela da população, mas uma construção humana, o estudante pode abandonar a posição da repetição empírica e lançar mão de outras possibilidades de relação com a Ciência e, da mesma forma, pensar ou repensar sua atuação em sala de aula. Para isso, urge a necessidade de futuros professores

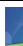


e de professores que já se encontram no exercício da docência, na Educação Básica, bem como, e principalmente, daqueles que fazem formação de professores compreenderem que

[...] a atuação profissional dos professores das Ciências, constitui um conjunto de saberes e práticas que não se reduzem a um componente domínio dos procedimentos, conceituações, modelos e teorias científicas." (DELIZOICOV et al, 2012, p. 33-34).

\section{Produtos educacionais: dos produtos elaborados aos resultados esperados}

Ante as concepções identificadas, nas respostas que nos foram dadas pelos estudantes dos Cursos de Licenciatura em Ciências Biológicas e Química, da Universidade Federal do Acre - Rio Branco, e a constatação de que, de forma geral, na maioria das vezes, tais concepções resultam de uma abordagem elementar e superficial da História da Ciência, nos cursos de formação de professores, e que tal situação pode resultar, a nosso ver, em implicações negativas à abordagem dos conteúdos em aulas de Ciências, uma vez que os mesmos tornam-se objetos de estudo sem estarem situados no tempo e na história e, por conseguinte, induzem os sujeitos a pensar a Ciência como sendo algo distante do seu tempo, da sua história e de suas vidas. Assim, optamos por elaborar como produtos de nossas pesquisas um vídeo e um curso on-line, de curta duração, que abordam a História da Ciência.

A versão dos produtos na íntegra pode ser acessada por meio do link http://ead.ufac.br/ava/course/view.php?id=373/. É neste ambiente que os interessados encontrarão os produtos [o curso on-line de curta duração e, em seu último módulo, o vídeo] organizados como resultado das pesquisas que desenvolvemos e cujos resultados foram acima apresentados ao leitor.

O curso on-line encontra-se organizado em quatro módulos, vejamos:

No módulo I, temos a apresentação e as orientações gerais ao cursista de como deve desenvolver suas atividades. Disponibilizamos ainda o link do filme Baraka, de Ron Fricke - 1993, um artigo de Cornélio Dias (2015) e uma atividade que deverá ser realizada após o cursista assistir ao filme e realizar a leitura do texto. Ressaltase que a realização dessa atividade é obrigatória para garantir o acesso ao módulo seguinte;

No módulo II, deixamos como texto base, o capítulo I - "Aspectos históricos da Ciência" - da dissertação elaborada em decorrência do estudo desenvolvido com estudantes de Ciências Biológicas, bem como textos complementares de Chalmers (1993) e Lopes (1999) e, da mesma forma, que no módulo anterior, disponibilizamos uma atividade que o cursista deverá realizar como pré-requisito para acessar o módulo III;

No módulo III, apresentamos ao cursista como texto base a Introdução e o Capítulo IV do Livro "Golem - O que você deveria saber sobre Ciências", de Collins e Pinch (2003) e uma nova atividade referente ao tema em tela;

No módulo IV, apresentamos ao cursista as possíveis relações entre as concepções de Ciência e as práticas pedagógicas desenvolvidas contidamente em sala de aula pelos professores de Ciências. Para isso, apresentamos como texto 
base o artigo "Epistemologia e Prática Pedagógica", de Paulo Evaldo Fensterseifer (2009) e compartilhamos o vídeo, produto educacional de mestrado, que aborda questões acerca da História da Ciência e suas implicações à prática pedagógica. $\mathrm{A}$ produção do vídeo emergiu da pesquisa desenvolvida com estudantes do Curso de Licenciatura em Química, cujos dados, foram objeto de discussão no presente artigo.

Após a finalização dos módulos, os cursistas serão direcionados à "Atividade Avaliativa" constituída de dez questões de múltipla escolha relativas ao conteúdo de todo o curso. Ressaltamos que a obtenção do certificado de $45 \mathrm{~h}$ do curso está condicionada à aprovação com, no mínimo, 70\% de aproveitamento nesta atividade.

Por fim, acreditamos que a elaboração e a disponibilização dos referidos produtos podem se configurar como uma proposta de formação continuada, para professores e futuros professores, e viabilizar a reflexão sobre o processo da construção da Ciência e as implicações dele para as práticas pedagógicas desenvolvidas em sala de aula de Ciências.

Da mesma forma, acreditamos que eles - o vídeo e o curso on-line - podem figurar como recursos didáticos para serem utilizados em salas de aula de Ciências, na Educação Básica, levando os estudantes a refletir sobre a gama de possibilidades de percepções da Ciência e, mais do que isso, sobre a pertinência de nos apropriarmos de uma concepção ampla, dinâmica, complexa e aberta.

\section{Considerações finais}

Ao iniciarmos nossas pesquisas, tínhamos como ponto central a identificação das concepções de Ciência dos futuros professores de Ciências Biológicas e Química, no sentido de refletir acerca de suas possíveis implicações quanto às práticas pedagógicas desenvolvidas no Ensino de Ciências.

Aqui, compreendemos Ciência como um constructo humano, historicamente situado, de forma que sua construção e/ou reconstrução está diretamente relacionada com o contexto social, cultural e político da sociedade. Assim, assumimos como concepção de Ciência a perspectiva do conhecimento construído/produzido por homens. Por isso, falível, mutável e resultado de diversas transformações, ao longo das décadas, que se apresentam para atender às demandas de uma determinada sociedade. Por isso, entendemos a Ciência como não sendo produtora de verdades indubitáveis, absolutas, mas parcelas de verdades que podem/devem ser relidas e reescritas, ou seja, parcelas de verdades transitórias.

Com a clareza acerca das concepções que assumiríamos, pois são, a nosso ver, as mais adequadas àquilo que nos propusemos a investigar e àquilo que acreditamos como sendo o mais próximo possível da Ciência e das práticas pedagógicas que defendemos, passamos à etapa seguinte da pesquisa que se referiu à identificação das concepções que os sujeitos da pesquisa possuem. Foi nesse movimento de análise dos dados que percebemos que as concepções apresentadas pelos sujeitos de nossas pesquisas, nos remetem a uma concepção de Ciência reducionista, descontextualizada e voltada para a sua área de formação, quais sejam: Ciências Biológicas ou Química. 
Sendo assim, em se tratando de relações possíveis entre concepção de Ciência e Ensino de Ciências, nossos estudos fizeram evidenciar três questões, vejamos: (a) concepções limitadas, fechadas, reducionistas, fragmentadas de Ciência [como conhecimento de uma área] que podem nos remeter às concepções igualmente limitadas e fragmentadas de ensino [conhecimentos a serem transmitidos] e de aprendizagem [conhecimentos a serem adquiridos]. Da mesma forma, foi possível perceber a prevalência de uma visão de Ciência centrada no estudo de saberes específicos, privilegiando uma ou outra área do conhecimento, pautada no rigor metodológico e na produção de verdades prontas e imutáveis, o que, a nosso ver, pode gerar em termos de ensino a centralização do ato de ensinar na figura do professor e a responsabilidade de aprender, no estudante. Por fim, imbricada em tais concepções de Ciência está, e não poderia ser diferente, a percepção de que ao professor cabe a tarefa de ensinar conteúdos relacionados com a sua área de atuação. Ou seja, com foco na vida (Ciências Biológicas), ou ainda, nos fenômenos da natureza (Química), excluindo-se assim, de certa forma, as possibilidades de desenvolvimento de um trabalho multi ou interdisciplinar e, da mesma forma, que viabilize significativas interações entre os sujeitos que participam dos processos de ensino e aprendizagem, de forma que ambos se sintam protagonistas da ação educativa.

Ante as fragilidades identificadas, quando acessamos as concepções de Ciência, de futuros professores da Educação Básica, emergiu a necessidade de elaborar e colocar à disposição de quem tiver interesse o vídeo e o curso on-line sobre "a História da Ciência e o Ensino de Ciências". Acreditamos que eles podem possibilitar discussões, reflexões, a construção de outras concepções de Ciência e, consequentemente, a função social do professor e do professor de Ciências, de forma que compreendamos que

[...] ninguém começa a ser professor numa certa terça-feira às 4 horas da tarde. Ninguém nasce professor ou marcado para ser professor. A gente se forma como professor permanentemente na prática e na reflexão sobre a prática. (FREIRE, 1991, p. 58).

\section{Referências}

BACHELARD, Gaston. A formação do espírito científico. Rio de Janeiro: Contraponto, 1997.

BRASIL. Coordenação de aperfeiçoamento de pessoal de nível superior. (1998). Portaria $\mathrm{n}^{\circ}$ 80, de 16 de dezembro de 1998. Disponível em: https://www.capes.gov.br/images/stories/download/ avaliacao/avaliacaon/1892015-Portaria-CAPES-080-1998.pdf. Acesso em: 12 de dez. 2019.

CAMARGO, Brigidu Vizeu; JUSTO, Ana Maria. IRAMUTEQ: um software gratuito para análise de dados textuais. Temas em psicologia. Ribeirão Preto, v.21, n.2, 2013.

CHALMERS, Allan. O que é ciência afinal? 2. ed. São Paulo: Brasiliense, 1993.

CHASSOT, Ático. A ciência através dos tempos. São Paulo: Moderna, 2003.

COLLINS, Harry; PINCH, Trevor. O Golem: o que você deveria saber sobre a ciência. Tradução Laura Cardelini Barbosa de Oliveira. São Paulo: UNESP, 2003.

4


DELIZOICOV, Demétrio; ANGOTTI, José André; PERNAMBUCO, Marta. Ensino de ciências: fundamentos e métodos. 3. ed. São Paulo: Cortez, 2012.

DIAS, Cornélio. A religião e a ciência pelo viés crítico do documentário audiovisual Baraka. Disponível em: https://www.docsity.com/pt/a-religiao-e-aciencia-pelo-vies-critico-do-documentario-audiovisual-baraka/4813630/. Acesso em: 12 de fevereiro de 2019.

FENSTERSEIFER, Paulo Evaldo. Epistemologia e prática pedagógica. Campinas: Revista Brasileira de Ciências do Esporte. v.30. n.3, 2009.

FREIRE, Paulo. Pedagogia da indignação: cartas pedagógicas e outros escritos. São Paulo: UNESP, 1991.

GRANGER, Gilles-Gaston. A ciência e as ciências. São Paulo: UNESP, 1994.

LOPES, Alice Ribeiro Casemiro. Conhecimento escolar: ciência e cotidiano. Rio de Janeiro: UERJ, 1999.

LOPES, Alice Ribeiro Casemiro. Bachelard: o filósofo da desilusão. Caderno Catarinense de Ensino de Física, Florianópolis, v. 3, n. 13, 1996.

MATURANA, Humberto, VARELA, Francisco. A árvore do conhecimento: as bases biológicas da compreensão humana. São Paulo: Palas Athenas, 2001.

MAYR, Ernest. Isto é biologia: a ciência do mundo vivo. São Paulo: Companhia das Letras, 2008.

MINAYO, Maria Cecília de Souza. (Org). Pesquisa social: teoria, método e criatividade. 6. ed. Petrópolis: Vozes, 1998.

MORIN, Edgar. Ciência com consciência. Rio de Janeiro: Bertrand Brasil, 2000 e 2010.

MORIN, Edgar. Método III: o conhecimento do conhecimento. 4. ed. Porto Alegre: Sulina, 2002.

PRIGOGINE, Ilya; STENGERS, Isabella. A nova aliança: metamorfose da ciência. 1. reimpr. Brasília: UnB, 1997.

Recebido: $22 / 03 / 20$

Aprovado: 28/05/20

Como citar: SILVA, F. S. O.; et al. Das concepções de Ciência à disponibilização de produtos educacionais: uma possibilidade para aprimorar práticas pedagógicas no Ensino de Ciências.

Revista de Estudos e Pesquisa sobre Ensino Tecnológico (EDUCITEC), v. 6, e123120, 2020.

Direito autoral: Este artigo está licenciado sob os termos da Licença Creative Commons-

Atribuição 4.0 Internacional. 